\title{
Should integrated residency programs supplant traditional programs in cardiothoracic surgery?
}

\author{
Vakhtang Tchantchaleishvili, MD, and George L. Hicks, MD
}

Because of the declining number of applicants to traditional cardiothoracic (CT) surgery residency programs in the past decade, ${ }^{1}$ innovative changes were introduced to increase the interest in CT surgery residency. ${ }^{2}$ The American Board of Thoracic Surgery led the way by approving the $4+3$ training model, removing the board certification requirement in general surgery, and, eventually, allowing the entrance of graduates of 5-year integrated vascular surgery residency programs to 2- or 3-year traditional CT surgery fellowships. Furthermore, the national societies introduced scholarships, such as the "Society of Thoracic Surgeons Looking to the Future Scholarship" and the "American Association for Thoracic Surgery Summer Intern Scholarship" (Table 1). Despite these significant innovations in the CT educational platform, no change has occurred in applications to traditional CT surgery programs, and a significant percentage of these programs continued to go unfilled, in part related to a tight job market, a shift in lifestyle priorities, and a poor understanding of CT surgery and its future potential by medical students and general surgery residents.

In 2007, the 6-year integrated CT surgery (I-6) residency model was approved by the Thoracic Surgery Residency Review Committee and generated significant interest and competition each year. This has been in part because of the low number of approved I- 6 programs ${ }^{3}$ and an additional large number of fully trained international CT surgeons eligible for the residency in the United States. ${ }^{4}$ However, the demand for the I-6 programs among US graduates has significantly outweighed the limited supply of positions as of 2013, ${ }^{5}$ and, based on the 2014 applicant quality, this training model appears to remain among the most competitive residencies in surgical specialties.

An analysis of the National Resident Matching Program match data for the past 20 years showed that the number of participating I-6 programs has been continuously growing, with none of these programs going unfilled. In contrast, the match results for the traditional CT surgery residency

\footnotetext{
From the Division of Cardiothoracic Surgery, Department of Surgery, University of Rochester Medical Center, Rochester, NY.

Disclosures: Authors have nothing to disclose with regard to commercial support. Received for publication Feb 19, 2014; revisions received April 25, 2014; accepted for publication May 2, 2014; available ahead of print June 9, 2014.

Address for reprints: George L. Hicks, MD, Division of Cardiothoracic Surgery, Department of Surgery, University of Rochester Medical Center, Box Cardiac Surgery, 601 Elmwood Ave, Rochester, NY 14642 (E-mail: George_Hicks@urmc. rochester.edu).

J Thorac Cardiovasc Surg 2014;148:379-80

$0022-5223 / \$ 36.00$

Copyright (c) 2014 by The American Association for Thoracic Surgery http://dx.doi.org/10.1016/j.jtcvs.2014.05.007
}

TABLE 1. Major innovative changes introduced to increase interest in CT surgery residency

\begin{tabular}{lc}
\hline \multicolumn{1}{c}{ Event } & Year \\
\hline $\begin{array}{l}\text { Removal of ABS certification as prerequisite for ABTS } \\
\text { certification }\end{array}$ & 2001 \\
Joint thoracic/general surgery track (fast-track or 4+3) pathway & 2006 \\
AATS Summer Intern Scholarship for medical students & 2007 \\
STS Looking to the Future Scholarship for general surgery & 2007 \\
$\quad$ residents & \\
Six-year integrated cardiothoracic surgery residency & 2007 \\
Eligibility of 5-y integrated vascular surgery graduates for & 2010 \\
$\quad$ traditional CT surgery training & \\
STS Looking to the Future Scholarship for medical students & 2011 \\
\hline
\end{tabular}

$C T$, Cardiothoracic; $A B S$, American Board of Surgery; ABTS, American Board of Thoracic Surgery; AATS, American Association for Thoracic Surgery; STS, Society of Thoracic Surgeons.

programs have remained relatively the same, at about $70 \%$, since the decrease in the early 2000s (Figure 1). Although some believe that by 2020 the comprehensive integrated CT surgery training beginning after medical school could become the only pathway leading to American Board of Thoracic Surgery certification, ${ }^{6,7}$ the reality is that the option of a traditional CT surgical training paradigm must be preserved.

Although the I-6 program was conceived to be equally beneficial for cardiac- and thoracic-oriented trainees, this particular training model has attracted more cardiacoriented residents. ${ }^{8}$ Traditionally, the decision regarding a career in thoracic surgery has been made later during the general surgery residency and not in the medical school. In addition, medical students interested in general thoracic surgery need to master a more formal general surgical skill set, followed by a traditional CT surgery residency, to experience patients with oncologic, gastrointestinal, and pulmonary pathologic entities. In addition, an increasing number of students have been graduating from medical school with an interest in CT surgery, ${ }^{9}$ who were not selected by the I-6 programs and would be expected to be candidates for traditional CT surgery programs after completing their general surgery residency. Furthermore, surgical residents interested in other specialties could change their mind and use the traditional CT surgery tract to pursue a career in CT surgery.

The integrated CT surgery paradigm will not be appropriate for many programs:

A lack of commitment by the CT surgery faculty to assume responsibility for fresh graduates of medical school and train them for 6 years 


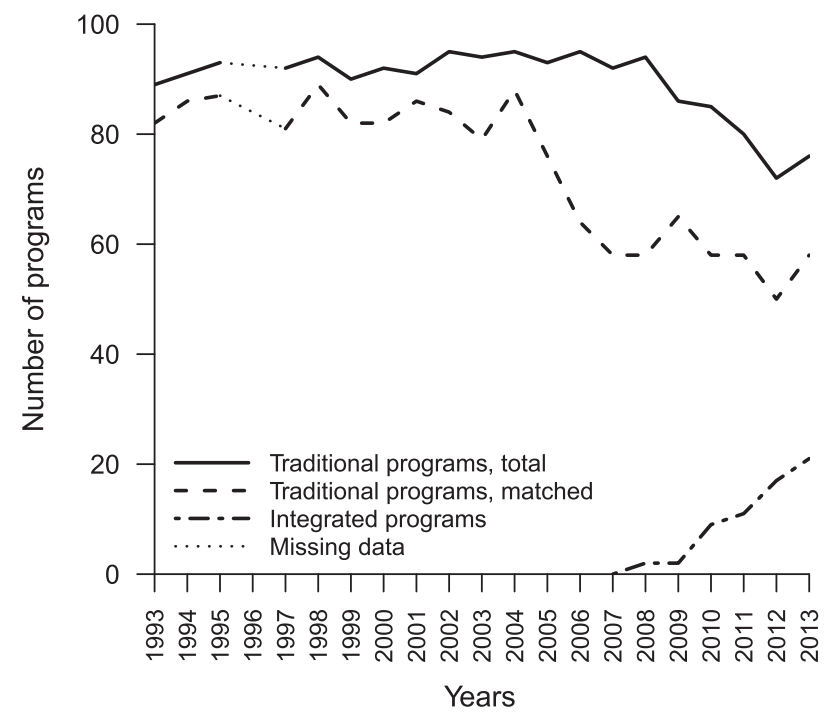

FIGURE 1. Number of total and unfilled programs in cardiothoracic (CT) surgery in the National Resident Matching Program match for the past 20 years. Since 2007, 6-year integrated CT surgery (I-6) programs began participating in the residency match and demonstrated a steady increase in numbers. To date, all I-6 programs have been filled through the match, and none have gone unmatched. In contrast, the match results of traditional CT surgery residency programs have remained at about $70 \%$ since the decrease in the early 2000s. Data from National Resident Matching Program. $^{5}$

A fear of losing applicants interested in general thoracic surgery

A poor relationship with the general surgery residency program

An inability to provide the index cases mandated for I-6 training by the Residency Review Committee

General surgery programs on probation

Finally, the I-6 training paradigm remains an experiment, with fewer than a handful of applicants having graduated from the program to date. As such, the outcome of this training approach in terms of success with American Board of Thoracic Surgery certification and, perhaps more importantly, the ability to independently and competently practice CT surgery is yet to be determined. More conservative directors of traditional CT surgery residency programs could be inclined to refrain from adopting the I-6 paradigm until these data are available.

Allowing the I-6 CT surgery training program to become the sole pathway could provide a barrier to many qualified and talented individuals from entering the profession of CT surgery. It remains crucial to provide a diversified training system, allowing a spectrum of opportunities for medical students, general surgery residents, integrated vascular surgery residents, and international residents and/or physicians to ensure a full complement of well-trained CT surgeons for the future.

\section{References}

1. Chitwood WR Jr, Spray TL, Feins RH, Mack MJ. Mission critical: thoracic surgery education reform. J Thorac Cardiovasc Surg. 2008;136:812-3.

2. Olinger GN. "Change in the wind": report from the 2000 Thoracic Surgery Directors Association retreat on Thoracic Surgery Graduate Medical Education. Ann Thorac Surg. 2001;72:1433-7.

3. Sainathan S. Integrated thoracic residency: the only pathway of thoracic surgery training in the future? Ann Thorac Surg. 2012;94:1374.

4. Chikwe J, Brewer Z, Goldstone AB, Adams DH. Integrated thoracic residency program applicants: the best and the brightest? Ann Thorac Surg. 2011;92: 1586-91.

5. National Residency Matching Program. 2013 Main Residency Match. Results and Data, National Residency Matching Program, April 2013. Available at: http:// b83c73bcf0e7ca356c80-e8560f466940e4ec38ed51af32994bc6.r6.cf1.rackcdn.com/ wp-content/uploads/2013/08/resultsanddata2013.pdf. Accessed December 19, 2013.

6. Baumgartner WA. ABTS, Past and Present: American Board of Thoracic Surgery Spring Meeting, October 2013. Available at: https://www.abts.org/media/7838/ DRB_ABTS_October2013_vNov13_2013.pptx. Accessed December 19, 2013.

7. Introduction/Background, Manual for Creating a Comprehensive Six-Year Integrated Curriculum in Cardiothoracic Surgery. Joint Council on Thoracic Surgery Education. Available at: http://www.tsda.org/wp-content/uploads/2012/12/Intro_ Background.pdf. Accessed April 18, 2014.

8. Tchantchaleishvili V, Barrus B, Knight PA, Jones CE, Watson TJ, Hicks GL Six-year integrated cardiothoracic surgery residency applicants: characteristics, expectations, and concerns. J Thorac Cardiovasc Surg. 2013;146:753-8.

9. Masroor S, Gasparri M. Invited commentary. Ann Thorac Surg. 2011;92:1591-2. 